\title{
Spinocerebellar ataxia 1 (SCA1) in the Japanese in Hokkaido may derive from a single common
}

\section{ancestry}

Akemi Wakisaka, Hidenao Sasaki, Akio Takada, Toshiyuki Fukazawa, Yoshihiro Suzuki, Takeshi Hamada, Kiyoshi Iwabuchi, Kunio Tashiro, Takashi Yoshiki

\begin{abstract}
Spinocerebellar ataxia 1 (SCA1) is caused by expansion of an unstable CAG triplet repeat located on the short arm of chromosome 6. Precise mapping has shown a positional relationship to closely linked markers in the order of D6S109-D6S274D6S288-SCA1-AM10GA-D6S89-EDN1 from centromere to telomere. The haplotype which cosegregated with the disease was determined in 12 Japanese pedigrees with SCA1. Although the alleles of the SCA1 haplotype varied from pedigree to pedigree, depending on the distance from the SCA1 locus, the affected and presymptomatic subjects carried the same alleles at D6S288 and D6S274. All the families with SCA1 had migrated from either Miyagi or Yamagata Prefectures, neighbouring areas in the Tohoku District, the northern part of Honshu which is the main island of Japan. It seems highly likely that SCA1 in the Japanese, at least those residing in Hokkaido, derives from a single common ancestry.
\end{abstract}

( $($ Med Genet 1995;32:590-592)

The dominantly inherited spinocerebellar ataxias are a cluster of genetically heterogeneous neurodegenerative disorders. Recent advances in molecular genetics have led to the identification of loci and specific gene abnormalities. Six different gene loci have been determined: SCA1 on chromosome $6 \mathrm{p} 24-\mathrm{p} 23,{ }^{1}$ SCA2 on $12 \mathrm{q} 23-\mathrm{q} 24,{ }^{2}$ SCA3 or MachadoJoseph disease (MJD) on 14q24-32, ${ }^{34}$ SCA4 on 16q24-ter, ${ }^{5}$ SCA5 on $11 \mathrm{q}^{6}{ }^{6}$ and dentatorubropallidoluysian atrophy (DRPLA) on $12 \mathrm{p} .{ }^{7}$
Among these disorders, abnormal expansions of the CAG trinucleotide repeat have been identified in patients with SCA $1,{ }^{8}$ DRPLA, ${ }^{7}$ and most recently with MJD. 9

The gene locus for SCA1 was first assigned on the basis of linkage with HLA. ${ }^{10}$ After demonstration of a tight linkage with D6S89, ${ }^{11}$ SCA1 was precisely mapped to chromosome $6 \mathrm{p} 24-\mathrm{p} 23$. The order of the gene is defined as D6S109-D6S274-D6S288-SCA1-AM10GAD6S89-EDN1 from centromere to telomere. ${ }^{812}$ Based on linkage analysis and the CAG triplet repeat causing SCA1 when expanded, SCA1 was considered to be a major disorder in dominant OPCA in the Japanese. ${ }^{13}$ Most SCA1 pedigrees in Hokkaido originate from the same area, Miyagi and Yamagata Prefectures, thereby suggesting a common origin, and we searched for haplotypes carrying the SCA1 gene in each pedigree. A comparison of these haplotypes with those of healthy populations suggested that SCA1 in the Japanese, at least those who migrated to Hokkaido from these Prefectures, may derive from a single common ancestry.

\section{Materials and methods SCA1 PEDIGREES}

Of the 12 pedigrees studied, 10 families were living in Hokkaido and two were from Yamagata Prefecture (table 1). The former are descendants of Japanese who migrated from Honshu, the main island of Japan. The original residence in Honshu could be traced in six of $10 \mathrm{Hokkaido}$ pedigrees. In each pedigree, affected subjects of either gender were distributed over successive generations. There were 46 affected subjects, 56 at risk subjects, and 23 spouses. Although the number of mem-

\begin{tabular}{|c|c|c|c|c|c|c|}
\hline \multirow[t]{2}{*}{ Family No } & \multicolumn{4}{|c|}{ Subjects sampled } & \multirow[t]{2}{*}{ Mean age at onset (SD) } & \multirow[t]{2}{*}{ Collected from } \\
\hline & Affected & At risk & Spouses & Total & & \\
\hline $\begin{array}{l}\text { P4 } \\
\text { P9 } \\
\text { P10 } \\
\text { P11 } \\
\text { P13 } \\
\text { P16 } \\
\text { P26 } \\
\text { P38 } \\
\text { P39 } \\
\text { P51 } \\
\text { P52 } \\
\text { P61 } \\
\text { Total }\end{array}$ & $\begin{array}{r}4 \\
4 \\
16 \\
2 \\
2 \\
4 \\
2 \\
2 \\
2 \\
1 \\
5 \\
2 \\
2 \\
46\end{array}$ & $\begin{aligned} 2 & (1)^{*} \\
3 & (0) \\
25 & (7) \\
2 & (0) \\
1 & (0) \\
4 & (0) \\
2 & (1) \\
1 & (0) \\
3 & (0) \\
6 & (2) \\
4 & (1) \\
3 & (1) \\
56 & (13)\end{aligned}$ & $\begin{array}{l}2 \\
0 \\
5 \\
1 \\
1 \\
4 \\
1 \\
0 \\
2 \\
2 \\
2 \\
3 \\
23\end{array}$ & $\begin{array}{r}8 \\
7 \\
46 \\
5 \\
4 \\
12 \\
5 \\
3 \\
6 \\
14 \\
8 \\
8 \\
126\end{array}$ & $\begin{array}{l}33 \cdot 8(2 \cdot 9) \\
46 \cdot 0(5 \cdot 3) \\
38 \cdot 0(8 \cdot 9) \\
31 \cdot 5(0 \cdot 7) \\
35 \cdot 0(0 \cdot 0) \\
22 \cdot 8(7 \cdot 5) \\
30 \cdot 5(6 \cdot 4) \\
52 \cdot 0(0 \cdot 0) \\
52 \cdot 0(0.0) \\
31 \cdot 8(10.0) \\
36 \cdot 0(2 \cdot 8) \\
29 \cdot 0(1 \cdot 4) \\
35.6(9.4)\end{array}$ & $\begin{array}{l}\text { Hokkaido } \\
\text { Hokkaido, Tokyo } \\
\text { Hokkaido } \\
\text { Hokkaido (Hakodate) } \\
\text { Hokkaido, Tokyo } \\
\text { Hokkaido (Hakodate) } \\
\text { Hokkaido (Hakodate) } \\
\text { Hokkaido } \\
\text { Hokkaido } \\
\text { Yamagata, Tokyo } \\
\text { Yamagata, Tokyo } \\
\text { Hokkaido }\end{array}$ \\
\hline
\end{tabular}

Department of

Internal Medicine, Yamagata University School of Medicine, Yamagata, Japan Y Suzuki

Department of Pathology, Kanagawa Rehabilitation Center, Atsugi, Kanagawa, Japan

K Iwabuchi

Correspondence to: Dr Wakisaka.

Received 22 September 1994

Revised version accepted for publication
5 April 1995

* Figures in parentheses indicate number of presymptomatic subjects. 
Table 2 D6S109-D6S274-D6S288-AM10GA-D6S89-EDN1 haplotype of SCA1 families

\begin{tabular}{llll}
\hline Pedigree No & Haplotype & CAG repeat size† & Migrated from \\
\hline P4 & $4-3-1-1-5-2$ & $49 \cdot 4(1 \cdot 8)$ & Miyagi Prefecture \\
P9 & $4-3-1-1-5-2$ & $46 \cdot 3(2 \cdot 1)$ & Miyagi Prefecture \\
P13 & $4-3-1-1-5-2$ & $46 \cdot 0(1 \cdot 4)$ & Miyagi Prefecture \\
P61 & $4-3-1-1-5-2$ & $53 \cdot 0(1 \cdot 0)$ & Miyagi Prefecture \\
P51 & $4-3-1-1-5-2$ & $48 \cdot 9(1 \cdot 2)$ & Yamagata Prefecture \\
P52 & $5-3-1-1-5-2$ & $49 \cdot 0(1 \cdot 7)$ & Yamagata Prefecture \\
P10 & $4-3-1-1-5-4$ & $48 \cdot 6(2 \cdot 1)$ & Miyagi Prefecture \\
P39 & $4-3-1-1-5-3$ & $46 \cdot 0(0 \cdot 0)$ & Unknown \\
P38 & $4-3-1-1-10-3$ & $45 \cdot 0(4 \cdot 2)$ & Miyagi Prefecture \\
P11 & $4-3-1-2-8-6$ & $49 \cdot 5(2 \cdot 1)$ & Unknown \\
P16 & $4-3-1-2-8-6$ & $52 \cdot 8(6 \cdot 4)$ & Unknown \\
P26 & $4-3-1-2-8-6$ & $50 \cdot 0(2 \cdot 6)$ & Unknown \\
\hline
\end{tabular}

* In pedigrees where there was recombination, the haplotype in members of the earliest generations is listed.

†Number of CAG repeats observed in patients and presymptomatic subjects is shown (mean (SE)). pedigree to pedigree depending on the distance from the SCA1 gene, all pedigrees shared the same alleles at D6S274 (allele 3) and D6S288 (allele 1). While most SCA1 haplotypes carried an allele 1 at the AM10GA locus, allele switches from 1 to 2 were evident in three of 12 families. The allele switches at AM10GA were always accompanied by those at the next adjacent loci of D6S89 and EDN1.

\section{LINKAGE DISEQUILIBRIUM}

We next examined the association (linkage disequilibrium) between the SCA1 gene and the markers. The allele frequencies of the markers were compared between SCA1 and the normal chromosome. A significant positive association with the SCA1 gene was obtained with allele 3 of D6S274 (12/12 in SCA1 chromosome $v$ $56 / 128$ in normal chromosome, $A=1 \cdot 00, D /$ $\left.\mathrm{Dmax}=0.32, \mathrm{pc}=7.99 \times 10^{-4}\right)$, allele 1 of D6S288 $(12 / 12$ in SCA1 $v 67 / 180$ in normal, $\mathrm{A}=1.00, \mathrm{D} / \mathrm{Dmax}=0.31, \mathrm{pc}=6.95 \times 10^{-5}$ ), allele 5 of D6S89 (8/12 in SCA1 $v 42 / 182$ in normal, $\mathrm{A}=0.74, \mathrm{D} / \mathrm{Dmax}=0.24, \mathrm{pc}=$ $\left.1.38 \times 10^{-2}\right)$, and allele 2 of EDN1 $(6 / 12$ in SCA1 $v 10 / 106$ in normal, $\mathrm{A}=0.81, \mathrm{D} /$ $\operatorname{Dmax}=0 \cdot 36, \mathrm{pc}=1 \cdot 38 \times 10^{-2}$ ), but not with the other two markers. These findings suggest that they are localised close enough to the SCA1 locus to maintain possible linkage disequilibrium, a result which parallels the finding that all the SCA1 pedigrees shared the same allele at D6S288 and D6S274.

A 10GA, D6S89, and EDN1. DNA ge A as described elsewhere. ${ }^{15}$

TEST FOR LINKAGE DISEQUILIBRIUM

A chromosome carrying ("SCA1 chromosome") and not carrying ("normal chromosome") the disease gene was determined by haplotype segregation analysis in each pedigree. The latter were derived from 23 healthy or unrelated subjects who had married into the family. Data on 73 healthy subjects who had married into the families with ataxia other than SCA1 were incorporated into data on controls. Allele frequencies of each marker on SCA1 and normal chromosomes were calculated by simple counting. For comparison, standardised linkage disequilibrium coefficient $(\mathrm{D} / \mathrm{Dmax})^{16}$ and Yule's association coefficient $(\mathrm{A})^{17}$ were calculated for each allele of the marker. The $p$ value was calculated by Fisher's exact probability test. Significance of association for the allele was evaluated by corrected p value (pc), which is the Fisher's $p$ value multiplied by the number of alleles compared.

\section{Results}

HAPLOTYPE SEGREGATION ANALYSIS

To determine the haplotype carrying the SCAl gene, we reconstituted the haplotype of the six loci (D6S109-D6S274-D6S288-AM10GAD6S89-EDN1) for each member. SCA1 cosegregated with a single haplotype in a pedigree specific manner, as shown in table 2 . Although the alleles of SCA1 haplotypes varied from

\section{Discussion}

The discovery of the CAG repeat polymorphism and apparent association of abnormally expanded alleles have established SCA1 as a triplet repeat disorder. ${ }^{8}$ A similar expansion of CAG repeats has been identified in subjects with spinobulbar muscular atrophy, Huntington's disease, DRPLA, ${ }^{7}$ and more recently in MJD. ${ }^{9}$ We have confirmed that SCA1 in the Japanese has the same molecular abnormality. ${ }^{14}$ The haplotype of D6S274 and D6S288 (3-1) was found in all pedigrees and the haplotype of D6S274-D6S288-AM10GA (3-1-1) in nine of 12 pedigrees. In the remaining three pedigrees, the SCA1 gene was inherited with the same haplotype of $3-1-2$, which may derive from a single recombination event on the ancestral haplotype of 3-1-1, because they also shared alleles at the next adjacent loci of D6S89 and EDN1 (table 2). Although the relationship between these three pedigrees is unknown, the fact that all three were from Hakodate City, the oldest city in Hokkaido that faces Honshu, supports this idea (table 1).

As shown in table 2, the original residence of the affected subjects could be traced in eight or Yamagata Prefectures, neighbouring prefectures in the Tohoku District, the northern part of the main island of Japan. Hokkaido is the northern-most island of Japan and has a unique history as "the last frontier". About 130 years ago, Hokkaido had only a small families. All had migrated from either Miyagi 
population of Ainu aborigines. Most present day Hokkaido residents are descendants of Japanese who migrated from various areas of Japan during the last 100 years. A variety of hereditary ataxia has been diagnosed in the residents of Hokkaido. When the original residence of these ataxic pedigrees was investigated, it became clear that most subjects with SCA1 were mostly from Miyagi and Yamagata Prefectures, whereas subjects with MJD were from Toyama and Niigata Prefectures. ${ }^{15}$ Since immigration to other areas of Japan was extensively prohibited during the Yedo era (from 1603 to 1868 AD), cultural and human communications were rare. The fact that one specific ataxia is most frequently observed in one specified area reflects this history.

Kwiatkowski et $a l^{12}$ reported that the alleles of AM10GA showed no recombination with SCA1 and varied among ethnic groups. Since the AM10GA allele of the Japanese patients is not identical to those noted in any other ethnic group, mutations in the SCA1 gene might possibly have occurred independently in each ethnic group. In the Japanese, the mutation may even have occurred in one founder who lived in Miyagi or Yamagata Prefectures. This event may not be in the distant past (about 17 generations ago) because linkage disequilibrium with EDN1, $4 \mathrm{cM}$ from SCA1 gene, is still maintained. However, linkage disequilibrium among seven tested markers, including the polymorphic CAG repeats of SCA1, was not observed among normal healthy populations (data not shown).

We are grateful to members of the families for their participation in this study. We thank $\mathrm{K}$ Masuda for technical assistance with the DNA analysis, Drs T Yanagihara, K Yoshida (Department of Neurology, Hokkaido University School of Medicine), K Shima, S Doi, A Takei (Sapporo Minami National Hospital), and others for contributions to this work. We thank $M$ Ohara for helpful suggestions about the manuscript. This work was supported by a grant in aid for Scientific Research on Priority Areas, Ministry of Education, Science and Culture, Japan in aid for Intractable Disease, Ministry of Health and Welfare, Japan, and Suhara Memorial Foundation.
1 Volz A, Fonatsch C, Ziegler A. Regional mapping of the gene for autosomal dominant spinocerebellar ataxia (SCA1) by localizing the closely linked D6S89 locus to 6p24.2p23.05. Cytogenet Cell Genet 1992;60:37-9.

2 Gispert $S$, Twells $R$, Orozco G, et al. Chromosomal assignment of the second locus for autosomal dominant cerebellar ataxia (SCA2) to chromosome 12q23-24.1. Nature Genet 1993;4:295-9.

3 Takiyama $Y$, Nishizawa $M$, Tanaka $H$, et al. The gene for Machado-Joseph disease maps to human chromosome
Mand 14q. Nature Genet 1993;4:300-4.

4 Stevanin G, Guern EL, Ravisé N, et al. A third locus for autosomal dominant cerebellar ataxia type I maps to chromosome 14q24.3-qter: evidence for the existence of a fourth locus. Am ₹ Hum Genet 1994;54:11-20.

5 Gardner K, Anderson K, Galster B, et al. Autosomal dominant spinocerebellar ataxia: clinical description of distinct hereditary ataxia and genetic localization to chromosome 16 (SCA4) in a Utah kindred. Neurology 1994;4(suppl 2): A361

6 Ranum LPW, Schut LJ, Lundgren JK, Ott HT, Livingston DM. Spinocerebellar ataxia type 5 in a family descended from the grandparents of president Lincoln maps to chromosome 11. Nature Genet 1994;8:280-4.

7 Koide R, Ikeuchi T, Onodera O, et al. Unstable expansion of CAG repeat in hereditary dentatorubral-pallidoluysian atrophy (DRPLA). Nature Genet 1994;6:9-13.

8 Orr HT, Chung M, Banfi S, et al. Expansion of an unstable trinucleotide CAG repeat in spinocerebellar ataxia type 1. Nature Genet 1993;4:221-6.

9 Kawaguchi Y, Okamoto T, Taniwaki M, et al. CAG expansions in a novel gene for Machado-Joseph disease at pansions in a novel gene for Machado-Joseph disease
chromosome 14q32.1. Nature Genet 1994;8:221-8.

10 Yakura H, Wakisaka A, Fujimoto S, Itakura K. Hereditary ataxia and HL-A genotypes. $N$ Engl f Med 1974;291: 154-5.

11 Zoghbi HY, Jodice C, Sandkuijl LA, et al. The gene for autosomal dominant spinocerebellar ataxia (SCA1) maps telomeric to the HLA complex and is closely linked to the D6S89 locus in three large kindreds. Am $\mathcal{F}$ Hum Genet 1991;49:23-30.

12 Kwiatkowski TJ Jr, Orr HT, Banfi S, et al. The gene for autosomal dominant spinocerebellar ataxia (SCA1) maps centromeric to D6S89 and shows no recombination, in nine large kindreds, with a dinucleotide repeat at the AM10 locus. Am f Hum Genet 1993;53:391-400.

13 Sasaki H, Wakisaka A, Tashiro K, Hamada T, Shima K. Linkage study of hereditary olivopontocerebellar atrophy in the Japanese: evidence for genetic heterogeneity. Clin Neurol (Tokyo) 1992;32:17-22.

14 Suzuki Y, Sasaki H, Wakisaka A, et al. Spinocerebellar ataxia 1 (SCA1) in the Japanese: analysis of CAG trinucleotide 1(SCA1) in the Japanese: analysis of CAG trinucleotide repeat expansion and instability of the repeat for

15 Sasaki H, Wakisaka A, Takada A, et al. Mapping of the gene for Machado-Joseph disease within a $3.6 \mathrm{cM}$ interval lanked by D14S291/D14S280 and D14S81, based on studies of linkage and linkage disequilibrium in 24 Japnese families. Am $\mathcal{F}$ Hum Genet 1995;56:231-42.

16 Chakravarti A, Buetow KH, Antonarakis SE, Waber PG, Boehm CD, Kazazian HH. Nonuniform recombination within the human $\beta$-globin gene cluster. Am $\mathcal{f}$ Hum Genet 1984;36:1239-58.

17 Kerem BS, Rommens JM, Buchanan JA, et al. Identification of the cystic fibrosis gene: genetic analysis. Science 1989 245:1073-80. 